\title{
Psychosocial Work Demands and Major Depressive Symptoms among Working Pregnant Women
}

\author{
Aïssatou Fall ${ }^{*}$, Lise Goulet ${ }^{1,2}$ and Michel Vézina ${ }^{2,3}$ \\ ${ }^{1}$ École de Santé Publique de l'Université de Montréal (ÉSPUM), Québec, Canada \\ ${ }^{2}$ Institut national de santé publique du Québec, Québec, Canada \\ ${ }^{3}$ Département de médecine sociale et préventive, Université Laval, Québec, Canada
}

\section{Abstract}

Objective: Evaluate the association between psychosocial work demands and major depressive symptoms among working pregnant women.

Methods: Karasek's abbreviated scale was used to measure psychosocial work demands (Job strain and "Iso-strain") and CES-D scale (Center for Epidemiological Studies Depression Scale) was used to measure major depressive symptoms (CES-D score $\geq 23$ ) among 3765 working pregnant women interviewed at 2426 weeks of pregnancy. Three series of logistic regression analyses were conducted to explore associations with: 1) the "demand-control" or "job strain" model; 2) the "demand-control-support" or "Iso-strain" models; 3) the three Karasek stress dimensions (job demand, job control and social support) forced individually into the same model. We examined the "buffer" hypothesis of "demand-control-support" model.

Results: Prevalence of major depressive symptoms was 9.8\% (95\% CI: $8.7-10.8 \%$ ). In all, $24.4 \%$ of pregnant working women were exposed to "high-strain" jobs (high demand and low control) and $17 \%$ to "Iso-strain" ("high-strain" job with low support at work). In bivariate and multivariate analyses, pregnant women who had "high-strain" or "Iso-strain" jobs were more likely to have major depressive symptoms. Psychosocial work demands were associated with the mental health of pregnant women, when other organizational and personal factors which they encountered outside the work settings were taken into account. The "buffer" hypothesis was refuted.

Conclusion: Our study confirms accumulated findings related to Karasek and Theorell's "demandcontrol" and "demand-control-support" theoretical models. The impact of the "demand-control-support" model and the critical role of social support at work have been demonstrated among working pregnant women.

\section{Background}

There is substantial proof linking symptoms of depression and major depression to working conditions [1-4]. Moreover, most authors agree about the causal nature of the relationship between psychosocial work demands and mental health problems [5-7].

Prevalence of depression and anxiety is highest during active life and reproductive years (15-44 years old) [8]. In addition, more and more women of childbearing age join the labour market, carrying out their productive and reproductive roles simultaneously.

Organizational and personal factors are closely associated with workers' mental health problems. Among organizational factors, "high-strain" job is an important risk factor [7,9-12]. The main organizational components known to be harmful to mental health are identified through two theoretical models: Karasek's "demandcontrol "model [9] and Karasek and Theorell's "demand-controlsupport" model [10]. According to the "strain" hypothesis [11] of the "demand-control" model, workers in "high-strain" jobs characterized by psychological demands or high demands (workload, time constraints, role conflict) and low decision latitude or low control (decision authority and skills discretion) will experience the most adverse reactions of psychological strain (fatigue, anxiety, depression and physical illness) [11,13]. In the "Iso-strain" hypothesis of "demand-control-support" model [11], jobs characterized by "highstrain" combined with low social support at work (instrumental and emotional support from colleagues and supervisors) or social

\section{Publication History:}

Received: July 10, 2017

Accepted: September 28, 2017

Published: September 30, 2017

\section{Keywords:}

Pregnancy, Major depressive symptoms, Job strain, "Iso-strain" isolation ("Iso-strain" jobs) are considered harmful to mental health. Furthermore the "buffer" hypothesis [11] of the "demand-controlsupport" model states that social support moderates the negative impacts of "high-strain". Both longitudinal and cross-sectional studies lend some support to the "strain" and "Iso-strain" hypotheses [11,13$14]$, but conclusions regarding the "buffer" hypothesis of the "demandcontrol-support" model are still unsettled $[11,14]$.

Numerous studies confirm the relationship between "highstrain" jobs and mental health problems such as depression, major depression, psychological distress, anxiety, burnout, and increased use of psychoactive drugs in men and women[1-4,11,12,15]. Some studies have demonstrated that women are more exposed than men to "high-strain" jobs $[16,17]$. However, no study has investigated the association between "Iso-strain" or "buffer" hypothesis of the "demandcontrol-support" model and major depressive symptoms among working pregnant women. Only associations between psychosocial work demands and pregnancy outcomes have been evaluated [18].

"Corresponding Author: Dr. Aïssatou Fall, École de Santé Publique de l'Université de Montréal (ÉSPUM), Québec, Canada; E-mail: a.fall@umontreal.ca

Citation: Fall A, Goulet L, Vézina M (2017) Psychosocial Work Demands and Major Depressive Symptoms among Working Pregnant Women. Int J Nurs Clin Pract 4: 253. doi: https://doi.org/10.15344/2394-4978/2017/253

Copyright: (c) 2017 Fall et al. This is an open-access article distributed under the terms of the Creative Commons Attribution License, which permits unrestricted use, distribution, and reproduction in any medium, provided the original author and source are credited. 
Citation: Fall A, Goulet L, Vézina M (2017) Psychosocial Work Demands and Major Depressive Symptoms among Working Pregnant Women. Int J Nurs Clin Pract 4: 253. doi: https://doi.org/10.15344/2394-4978/2017/253

The objective of our study was to evaluate associations between psychosocial work demands and major depressive symptoms among working pregnant women.

\section{Methodology}

Data analyzed are from the Montreal Prematurity Study [19], a prospective cohort study of spontaneous preterm birth among 5,337 women who delivered from 1999 to 2004 in four large maternity hospitals affiliated with McGill University and Université de Montréal. Recruitment procedures have been described in detail previously [1920]. The project was approved by the ethics committees of all four participating hospitals. Briefly, women were recruited when they presented for routine ultrasound examinations (16-20 weeks), for prenatal blood drawing (8-12 weeks) or in hospital prenatal clinics (before 24 weeks). Eligibility criteria were as follows: age $\geq 18$ years at expected date of delivery, singleton gestation, and fluency in French or English. Women presenting a severe chronic illness or a condition that increased the risk of preterm birth were excluded from the study. Women who accepted to participate in the study were requested to return to a special research clinic at 24-26 weeks of gestation. Data were collected from a paper questionnaire administered face to face by research nurses.

Our study focuses on the analysis of 3,765 (70.5\%) working pregnant women who had reported working at paid jobs at least 15 hours a week and for a minimum of four consecutive weeks since they had gotten pregnant.

The following variables were analyzed:

\section{Major depressive symptoms}

The 20-item version of the CES-D scale (Center for Epidemiological Studies Depression Scale) by Radloff [21] was used to identify the presence and assess the severity of depressive symptoms in our sample. The scale has excellent internal consistency, with Cronbach's alpha ranging from 0.85 (general population) to 0.90 (psychiatric patients), and adequate test-retest reliability (0.54)[21]. We used the cutoff of CES-D score $\geq 23$ proposed by Radloff and Locke [22] to indicate the presence of major depressive symptoms. Considering that certain symptoms of depression overlap with symptoms of pregnancy (e.g. appetite change and fatigue).

\section{Psychosocial work demands}

We used the abbreviated version of Karasek's scale (Job Content Questionnaire)[10]validated by Fenster [23] to measure psychosocial work demands. This version contains 13 items and measures three dimensions: job demand (four items), job control (five items), and social support at work (four items). Each item was rated on a 4-point Likert scale (strongly disagree, disagree, agree, strongly agree). The abbreviated scale maintains internal consistencies of $0.60-0.88$ (Cronbach's $\alpha$ ) versus $0.61-0.81$ for the entire instrument $[10,23]$. The three Karasek stress dimensions were studied separately and simultaneously according to the "demand-control" and the "demandcontrol-support" models.

To measure job strain, the job demand and job control scales were converted to dichotomous measures according to a median split: high demand (value above the median), low control (value below the median) and low social support at work (value below the median). Four categories of work were defined by a combination of job demand and job control scales: "low strain" (low demand and high control) (reference); "passive" (low demand and low control); "active" (high demand and high control); and "high-strain" job (high demand and low control). The combination of "high-strain" job and social support resulted in four groups: "no high strain/high support" (reference); "no high strain/low support"; "high strain /high support"; and "high strain/low support" or "Iso-strain". The three Karasek stress dimensions (job demand, job control and social support) were also analyzed separately.

\section{Occupational characteristics}

\section{Type of occupation}

The National Occupational Classification 2006 (NOC) [24] was used to classify the women's occupations according to skill level and skill type. Skill type is based on the type of work performed but also reflects the field of training or experience normally required for entry into the occupation. Skill type corresponds to a sector of activity: 1) Management Occupations (reference); 2) Business, Finance and Administration Occupations; 3) Natural and Applied Sciences and Related Occupations; 4) Health Occupations; 5) Occupations in Social Sciences, Education, Government Service and Religion; 6) Occupations in Art, Culture, Recreation and Sport; Sales and Services Occupations; 7) Trades, Transport and Equipment Operators and Related Occupations; 8) Occupations Unique to Primary Industry; 9) Occupations Unique to Processing, Manufacturing and Utilities.

In the NOC, skill level corresponds to the type and/or amount of training or education typically required to work in an occupation. The NOC includes four skill levels: management; professional (university degree)(reference); technical (post-secondary education at a community college or apprenticeship training); intermediate (secondary school or job-specific training); elemental (on-the-job training) [24].

\section{Working conditions}

The questionnaire documented the following working conditions: number of weeks worked since the beginning of the pregnancy; number of hours per week; night or rotating shift; posture at work (standing with or without moving around); lifting heavy loads (> $10 \mathrm{Kg}$ or $20 \mathrm{lbs}$.).

Risk accumulation variable was developed from the following variables: high-strain and low social support at work; shift work (night or rotating); hours per week $\geq 40$ hours, standing position with or without moving around ( $\geq 4$ hours); and lifting $>10 \mathrm{Kg}$ or $20 \mathrm{lbs}$.

\section{Demographic and socioeconomic characteristics, lifestyle habits, chronic health problems, chronic stressors}

The following characteristics were measured at the time of the interview: mother's age; country of birth (Canada, other countries); parity (primiparous, multiparous); single-parent family (yes/no); highest level of education; annual household income; smoking during pregnancy (non-smoker, occasionally/regularly); alcohol consumption during pregnancy (no alcohol, $\leq 2$ times/month, several times/week) and chronic health problems during pregnancy (none, at least one) 
Citation: Fall A, Goulet L, Vézina M (2017) Psychosocial Work Demands and Major Depressive Symptoms among Working Pregnant Women. Int J Nurs Clin Pract 4: 253. doi: https://doi.org/10.15344/2394-4978/2017/253

Page 3 of 6

Measurement of stressful life events, lack of money for basic needs, marital strain and social support outside work was previously described in detail [20]. Stressful life events since the beginning of pregnancy (moving, unwanted cohabitation, theft, natural catastrophes, racial discrimination, accidents, job loss, separation or divorce, woman herself or family member seriously ill, death of a spouse or loved one) were summed and a three-category variable was created (none, one or two, more than two-life events)[20]. Lack of money for basic needs (food, heating, electricity, bills, rent, medications and other necessities) since the beginning of pregnancy were summed and the variable was dichotomized as yes (for those who have lacked money for three or more essential needs indicative of poverty) or no (all others)[20]. More over, the measure of marital strain, chronic stress associated with marital relationship or partner (attitudes and behaviors of the couple) has distinguished categories, assigning women who did not have partners to a separate category to avoid their exclusion: no marital strain, low or moderate marital strain, high marital strain, no partner [20]. Finally, social support outside of work included the number of people who can provide help when needed in five functions of support (instrumental, emotional, informative, normative, and companionship)was dichotomized as absent (those with unmet needs in one or more of the five functions) or present (those without needs and those whose needs were met) [20].

\section{Data analyses}

First we performed univariate analyses to describe sociodemographic, socioeconomic, lifestyle habit, stressor variables and organizational characteristics, and bivariate analyses to explore associations between psychosocial work demands, major depressive symptoms and each covariate using Chi square tests.

Second, we calculated the prevalence of major depressive symptoms according to psychosocial work demands and each covariate, and assessed the association between these variables and major depressive symptoms using logistic regression (unadjusted OR and 95\% CI).

Then we constructed multivariate logistic models to evaluate associations between psychosocial work demands and major depressive symptoms among working pregnant women. In order to select potential confounders, we performed a series of analyses and calculated for each covariate the percentage change in the OR for

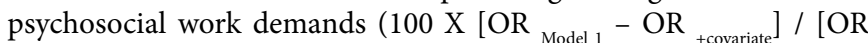
Model 1 - 1]) [25], only those factors that individually produced at least a 10\% change [26] in the OR for psychosocial work demands were kept for the multivariate analysis. Three series of logistic regression analyses were conducted to explore associations with: 1)the "demandcontrol" or "job strain" model; 2) the "demand-control-support" or "Iso-strain" models; 3) the three Karasek stress dimensions (job demand, job control and social support) forced individually into the same model. For each series of analyses, the effect of explanatory variables was assessed by staggered entry of different adjustment variables: 1) Model 1: only for psychosocial work demands; 2) Model 2: adjusted for Model 1 variables and other work characteristics; and 3) Model 3: adjusted for Model 2 variables and sociodemographic, socioeconomic, lifestyle habit characteristics and stressors.

Finally, we examined the multiplicative interaction between "highstrain" X support (two-way interactions) for the "buffer" hypothesis of "demand-control-support" model. The modifying effect of social support at work was also evaluated by stratification.
All reported $p$-values are 2 -sided and $p$-value $<0.05$ was considered statistically significant.

Goodness of fit was assessed using the Hosmer and Lemeshow test [27]. Moreover, ROC (Receiver Operating Characteristic) curves were plotted and areas under the curve were analyzed and tested $(\mathrm{p}<0.05)$ the goodness of fit of different models.

All analyses were performed using IBM $^{\star}$ SPSS $^{\star}$ Statistics 20 for Windows.

\section{Results}

The sociodemographic and socioeconomic characteristics as well as working conditions of pregnant women according to psychosocial work demands and major depressive symptoms are presented in Table 1 (Supplementary File).

At 24 to 26 weeks of pregnancy, prevalence of major depressive symptoms (CES-D score $\geq 23$ ) was $9.8 \%$ (95\% CI: 8.7-10.8\%). Women who reported major depressive symptoms during pregnancy were significantly younger, more often non-Canadian-born, single-parent family, and lower educated compared to others (Table 1).

The median split of the scales resulted in $48.1 \%$ of the sample scoring above the median on the demand scale ("high demand"), $56.5 \%$ scoring below the median on decisional latitude ("low control"), and $52.7 \%$ scoring below the median on social support at work ("low social support") (Table 1). In all, 24.4\% (893/3660) of them were exposed to "high-strain" jobs and 17\% (592/3501) to "Iso-strain" jobs; the latter represented $69.1 \%$ of pregnant women exposed to "highstrain" jobs (Table 1 ).

In our sample, $14.7 \%$ (95\% CI: $12.5-17.2 \%)$ of pregnant women who had been exposed to "high-strain" jobs $(\mathrm{P}<0.0001)$ presented major depressive symptoms (Table 1). They were mostly in two sectors of activity: Business, Finance and Administration; Sales and Services.

As well, $17 \%$ (95\% CI: 14.1-20.2\%) of women who had been exposed to "Iso-strain" had major depressive symptoms $(\mathrm{P}<0.005)$ (Table 1) and were in the following sectors of activity: Business, Finance and Administration; Health; Processing, Manufacturing and Utilities; Transport and Equipment; Sales and Services.

Univariate logistic regression analysis showed that the prevalence of major depressive symptoms was significantly higher among the group of women with "high-strain" (OR=3.34; 95\% CI: 2.27-4.92; $\mathrm{P}<0.0001)$ and "Iso-strain" jobs $(\mathrm{OR}=3.25$; 95\% CI: 2.38-4.45; $\mathrm{P}<0.0001)$ (Table $1)$.

Skill types and levels were statistically associated with major depressive symptoms and "high-strain" jobs. Among work characteristics, irregular schedules (night or rotating shift), standing position with or without moving around and lifting heavy loads were strongly associated with major depressive symptoms. In all, $24.1 \%$ of pregnant women exposed to "high-strain" jobs had at least three professional risk factors; there was a statistically significant association between accumulation of risks and major depressive symptoms. The personal risk factors strongly associated with major depressive symptoms were acute stressful events, lack of social support outside work, relationship problems with a partner, and chronic health problems (Table 1). 
Citation: Fall A, Goulet L, Vézina M (2017) Psychosocial Work Demands and Major Depressive Symptoms among Working Pregnant Women. Int J Nurs Clin Pract 4: 253. doi: https://doi.org/10.15344/2394-4978/2017/253

Page 4 of 6

Women working in Sales and Services Health, Business, Finance and Administration, exposed to "high-strain" jobs who had major depressive symptoms, worked more than 40 hours/week, carried heavy loads, and had predominantly standing working postures without moving $\geq 7$ hours/day and rotating shift. Those most affected were intermediate (waitresses and saleswomen) and elementary (cashiers) sales and services workers, office staff (clerks) and specialized personnel in administration in office (secretaries), professional care staff (nurses), and support staff (orderlies, dental assistants) in health services (results not shown).

The independent effect of psychosocial work demands on major depressive symptoms was revealed in three series of logistic regression analyses, the results of which are summarized in Table 2 (Supplementary File).

\section{"Strain" hypothesis of "demand-control" model}

"High-strain" and "passive" jobs were strongly associated with major depressive symptoms (Model 1 and 2), but only "high-strain" jobs (OR 1.68; 95\% CI: 1.08 to 2.62) remained statistically significant after adjustment for all variables (Model 3). Other variables associated with major depressive symptoms (CES-D score $\geq 23$ ) were as follows: working in the sales and services sector; processing, manufacturing and utilities; lifting heavy loads; low level of education; having experienced acute stressful events; marital strain; lacking social support outside work; and having chronic health problems (Model 3).

Results confirmed the "strain" hypothesis. Pregnant women exposed to "high-strain" jobs showed significantly higher major depressive symptoms (14.7\%) than women in the other three groups: "passive" (11.4\%), "active" (6.2\%) and "low strain" (4.9\%).

\section{"Iso-strain" hypothesis of "demand-control-support" model}

The odds ratios of "high strain /low support" (OR 1.85; 95\% CI: 1.29 to 2.65 ) and "no high strain /low support" (OR 1.43; 95\% CI: 1.03 to 1.97) subgroups were reduced in size but remained significant after adjusting for all variables. Moreover personal and professional variables associated with the full "job strain" model remained associated in this model (Model 3) (Table 2)(Supplementary File).

In fact, the ORs for major depressive symptoms increase when low social support at work is added to the job strain variable (OR 1.68 for "high-strain" job and OR 1.85 for "Iso-strain"). According to the "Isostrain" hypothesis, the higher the demands and the lower the control and support, the higher was the prevalence of major depression symptoms (17\%).

Pregnant women in "no high strain/low support" group had significantly higher major depressive symptoms compared with those with "no high strain/high support" (10.3\% vs. $5.9 \%)$.

\section{Individual dimensions of psychosocial work demands}

Only low social support at work (OR 1.46; 95\% CI: 1.10 to 1.93 ) was associated with CES-D score $\geq 23$ after adjusting for all three Karasek's dimensions (Model 3) (Table 2) (Supplementary File).

\section{"Buffer" hypothesis of "demand-control-support" model}

No significant multiplicative interaction ( $\mathrm{P}$ value $=0.698$ ) was found between "high-strain" and social support at work (two-way interaction) (Table 3) (Supplementary File).
Social support did not modify the association between major depressive symptoms and "high-strain" jobs for every exposure groups; after adjusting for all variables, the OR did not vary meaningfully with the level of social support (stratification): high social support at work (OR 1.15; 95\% CI: 0.64 to 2.07 ) and low social support at work (OR 1.32; $95 \%$ CI: 0.95 to 1.83 ) (results not shown).

\section{Discussion}

At 24 to 26 weeks of pregnancy, prevalence of major depressive symptoms was $9.8 \%$ (95\% CI: 8.7-10.8\%) for all pregnant women. In our sample, $14.7 \%$ (95\% CI: $12.5-17.2 \%)$ of pregnant women who had been exposed to "high-strain" jobs and 17\% (95\% CI: $14.1-20.2 \%)$ of women who had been exposed to "Iso-strain" presented major depressive symptoms. The average prevalence rate of prenatal depression is estimated to be approximately $12 \%$ [28], while prevalence may vary up to $18 \%$ [29] according to mode of assessment and socioeconomic conditions. Orr et al. have shown prevalence of major depressive symptoms (CES-D score $\geq 23$ ) ranging from $16.2 \%$ to $27.5 \%$ for multiracial pregnant women [30].

Our study is one of the few to look at organizational, personal characteristics and major depressive symptoms of pregnant working women. We found significant statistical associations between major depressive symptoms and psychosocial work demands. Our results are consistent with a number of cross-sectional[1,4,13,17] and longitudinal studies $[3,16,31]$ as well as with some meta-analyses [5-7].

Our study confirms the "Strain" and "Iso-strain" hypotheses: "highstrain" and "Iso-strain" are strong risk factors for major depressive symptoms among pregnant working women. The impact of the "demand-control-support" theoretical model and the critical role of social support at work have been demonstrated [11,13,31],low social support at work is associated with major depressive symptoms. This finding is consistent with the literature, and other studies have shown that support is the sub-scale most strongly associated with negative affects $[13,32]$.

Only a few studies have demonstrated the "buffer" hypothesis of the "demand-control-support" model [11,14,33], but our study did not find significant multiplicative interaction for this theoretical model. Social support did not modify significantly the association between "high-strain" jobs and major depressive symptoms. In fact, support for the two-way interactions on "high-strain" is relatively weak, and support for the three-way interaction (demand $\mathrm{x}$ control $\mathrm{x}$ support) is marginal [34]. Most of the studies used an additive term and subgroup analyses to capture the relationship between job demands, job control and social support, but are it necessary to find interactive multiplicative effects [34].

The use of "Iso-strain" categorisation allowed us to identify sectors of activity and pregnant working women at risk for major depressive symptoms. Workers in the Sales and Services, Business, Finance and Administration, and Processing, Manufacturing and Utilities sectors were more exposed to psychosocial work demands and major depressive symptoms. Among work characteristics, irregular schedules (night or rotating shift) and lifting heavy loads were strongly associated with mental health problems. Irregular schedules were an expected risk factor and an association had been observed in previous studies of both men and women [35]. Personal risk factors strongly associated with major depressive symptoms were acute 
Citation: Fall A, Goulet L, Vézina M (2017) Psychosocial Work Demands and Major Depressive Symptoms among Working Pregnant Women. Int J Nurs Clin Pract 4: 253. doi: https://doi.org/10.15344/2394-4978/2017/253

Page 5 of 6

stressful events, lack of social support outside work, marital strain, and chronic health problems. It has been demonstrated that lack of social support outside work [36] and acute events [37] are predictive factors for mental health problems.

Some of the strengths of our study are the size of our population and the fact that we were able to control for different sets of confounding variables such as work characteristics and sociodemographic, socioeconomic, lifestyle habit, acute and chronic stressor variables.

Certain limitations should be taken into consideration. The representativeness of working women in our study population was not tested, and even though four study hospitals serve a broad demographic, socioeconomic and linguistics (French- and Englishspeaking populations) spectrum across the island of Montréal, caution is needed in generalizing our results. This is especially true since it was revealed that the pregnant women recruited into the Montreal Prematurity Study [19] were more educated than women who gave birth in hospitals located in the census metropolitan region of Montréal [38].

The major limitation of this study is its cross-sectional design, which does not allow us to prove the existence of causal relationships. In addition, Karasek's scale and CES-D scale were self-reported; however, subjectivity biases linked to this data collection method can be minimized since the scales we used are standardized and validated as excellent psychometric tools. The simultaneous collection of exposure and health data from pregnant women may have created circular reasoning. Finally, pregnant women's personal history of depression was not documented. However, we should note the strong contribution of confounding variables included in the analyses.

Despite these limitations, our study demonstrates a solid association between major depressive symptoms and psychosocial work demands in a population of pregnant working women, and allows us to offer suggestions for prevention. Some working conditions seem to be detrimental to the mental health of pregnant women when we consider personal characteristics and other stressful situations which they encountered outside work settings.

We need to examine the interaction between job control and social support at work on common mental disorder and whether the interaction will differ by the level of job demands in female worker Furthermore, they would be informative in understanding complex mechanisms of the psychosocial work characteristics to common mental disorders as well as evaluating contemporary job stress models [39].

We would recommend improving capacity related to protection and promotion of mental health in workplaces through evaluations of psychosocial risk factors, management, training and awareness of employers and employees. In addition, appropriate indicators and tools should be developed to monitor mental health related to work stress so as to improve diagnosis and treatment of depression by health professionals by targeting populations at highest risk, especially women in the prenatal period.

\section{Competing Interests}

The authors declares that they have no competing interests.

\section{References}

1. Rugulies R, Bültmann U, Aust B, Burr H (2006) Psychosocial work environment and incidence of severe depressive symptoms: prospective findings from a 5-year follow-up of the Danish work environment cohort study. Am J Epidemiol 163: 877-887.

2. Wang JL (2005) Work Stress as risk factor for major depressive episode(s). Psychol Med 35: 865-871.

3. Stansfeld SA, Fuhrer R, Shipley M, et al. (1999) Work characteristics predict psychiatric symptoms: prospective results from the Whitehall II Study. Occup Environ Med 56: 302-307.

4. Niedhammer I, Goldberg M, Leclerc A, Bugel I, David S (1998) Psychosocial factors at work and subsequent depressive symptoms in the Gazel cohort. Scand J Work Environ Health 24: 197-205.

5. Netterstrøm B, Conrad N, Bech P, Fink P, Olsen O, et al. (2008) The relation between work-related psychosocial factors and the development of depression. Epidemiol Rev 30: 118-132.

6. Bonde JP (2008) Psychosocial factors at work and risk of depression: a systematic review of the epidemiological evidence. Occup Environ Med 65: 438-445.

7. Stansfeld SA, Candy B (2006) Psychosocial work environment and menta health - a meta-analytic review. Scand J Work Environ Health 32: 443-462.

8. Plaisier I, de Bruijn JG, Smit JH, de Graaf R, Ten Have M, et al. (2008) Work and family roles and the association with depressive and anxiety symptoms: Differences between men and women. J Affect Disord 105: 6372.

9. Karasek RA (1979) Job demands, job decision latitude and mental strain implications for job redesign. Administrative Science Quarterly 24: 285-309.

10. Karasek RA, Theorell T (1990) Healthy work: stress, productivity, and the reconstruction of working life. New York: Basic Books.

11. Van der Doef M, Maes S (1999) The Job Demand-Control-Support model and psychological well-being: a review of 20 years of empirical research. Work Stress 13: 87-144.

12. Ylipaavalniemi J, Kivimäki M, Elovainio M, et al. (2005) Psychosocial work characteristics and incidence of newly diagnosed depression: a prospective cohort study of three different models. Soc Sci Med 61:111-122.

13. Sanne B, Mykletun A, Dahl AA, Moen BE, Tell GS (2005) Testing the job Demand-Control-Support model with anxiety and depression as outcomes: The Hordaland Health Study. Occup Med (Lond) 55: 463-473.

14. De Lange A, Taris T, Kompier M, et al. (2003) The Very Best of the Millenium: longitudinal research and the Demand-Control-(Support) Model. J Occup Health Psychol 8: 282-305

15. Moisan J, Bourbonnais R, Brisson C, Gaudet M, Vezina, et al. (1999) Job strain and psychotropic drug use among white-collar workers. Work and Stress 13: 289-298.

16. Clays E, De Bacquer D, Leynen F, Kornitzer M, Kittel F, et al. (2007) Job stress and depression symptoms in middle-aged workers-prospective results from the Belstress study. Scand J Work Environ Health 33: 252259.

17. Vézina M, Bourbonnais R, Marchand A, et al. (2008) Stress au travail et santé mentale chez les adultes québécois. Enquête sur la santé dans les collectivités canadiennes (cycle 1.2), Québec, Institut de la statistique du Québec 50 p.

18. Mutambudzi M, Meyer JD, Warren N, Reisine S, et al. (2011) Effects of psychosocial characteristics of work on pregnancy outcomes: a critical review. Women Health 51: 279-297.

19. Kramer MS, Goulet L, Lydon J, Séguin L, McNamara H, et al. (2001) Socioeconomic disparities in preterm birth: causal pathways and mechanisms. Paediatr Perinat Epidemio I15: 104-123.

20. Fall A, Goulet L, Vézina M (2013) Comparative study of major depressive symptoms among pregnant women by employment status. Springerplus 2: 201

21. Radloff LS (1977) The CES-D scale: a self-report depression scale for research in the general population. Applied Psychological Measurement 1: $385-401$. 
Citation: Fall A, Goulet L, Vézina M (2017) Psychosocial Work Demands and Major Depressive Symptoms among Working Pregnant Women. Int J Nurs Clin Pract 4: 253. doi: https://doi.org/10.15344/2394-4978/2017/253

22. Radloff LS, Locke BZ (1986) The Community Mental Health Assessment Survey and CES-D scale. In: Weissman MM, Myers JK, eds. Community Surveys of Psychiatric Symptoms. New Brunswick, NJ: Rutgers University Press177-187.

23. Fenster L, Schaefer C, Mathur A, Hiatt RA, Pieper C, et al. (1995) Psychological stress in the workplace and spontaneous abortion. Am J Epid142: 1176-1183.

24. Statistique Canada (2001) Classification nationale des professions pour statistiques (CNP). Publication no 12-583-XPF au catalogue, Statistique Canada.

25. MacKinnon DP, Krull JL, Lockwood CM (2000) Equivalence of the mediation, confounding and suppression effect. Prev Sci 1: 173-181.

26. Rothman KJ, Greenland S (1998) Modern epidemiology. Lippincott-Raven Publishers Philadelphia.

27. Hosmer DW, Lemeshow S (1989) Applied logistic regression. John Wiley and Sons. Toronto, 307p

28. Gavin NI, Gaynes BN, Lohr KN, Meltzer-Brody S, Gartlehner G, et al. (2005) Perinatal depression: a systematic review of prevalence and incidence. Obstet Gynecol 106: 1071-1083.

29. Marcus SM, Flynn HA, Blow FC, Barry KL (2003) Depressive symptoms among pregnant women screened in obstetrics settings. J Womens Health 12: $373-380$

30. Orr ST, Blazer DG, James SA (2006) Racial disparities in elevated prenatal depressive symptoms among black and white women in eastern north Carolina. Ann Epidemiol 16: 463-468.

31. Bildt C, Michelsen $\mathrm{H}$ (2002) Gender differences in the effects from working conditions on mental health: a 4-year follow-up. Int Arch Occup Environ Health 75: 252-258.

32. Pelfrene E, Vlerick P, Kittel F, Mak RP, Kornitzer M (2002) Psychological work environment and psychological well-being: assessment of the buffering effects in the job demand-control(-support) model in BELSTRESS. Stress Health 18: 43-56.

33. Parkes KR, Mendham CA, Von Rabenau C (1994) Social support and the demand-discretion model of job stress: Tests of additive and interactive effects in two samples. Journal of Vocational Behavior 44: 91-113.

34. Bradley G (2004) A Test of Demands-Control- Support Model. Job Strain and healthy work. Journal of Applied Psychology. Griffith University, Australia.

35. Bourbonnais R, Larocque B, Brisson C, et al. (2000) Environnement psychosocial du travail, dans : Enquête sociale et de santé 1998, Québec Institut de la statistique du Québec, coll. «La santé et le bien-être » chapitre $27: 571-583$

36. Godin I, Fontaine J, Kittel F (2004) Social support at- and outside work, any impact on mental health? Eur J Public Health 14: 13-15.

37. Kendler KS, Karkowski LM, Prescott CA (1999) Causal relationship between stressful life events and the onset of major depression. Am J Psychiatry 156: 837-841.

38. Kramer MS, Wilkins R, Goulet L, Séguin L, Lydon J, et al. (2009) Investigating socio-economic disparities in preterm birth: evidence for selective study participation and selection bias. Paediatri Perinat Epidemio 123: 301-309.

39. Choi B, Östergren PO, Canivet C, Moghadassi M, Lindeberg S, et al. (2011) Synergistic interaction effect between job control and social support at work on general psychological distress. Int Arch Occup Environ Health 84: 77 89. 